DOI: 10.24014/jdr.v30i1.7059

\title{
POLITIK SELEBRITI: PERLAWANAN TERHADAP SISTEM (Studi Kasus Gaya Komunikasi Politik pada Kandidat Presiden Ukraina Volodymyr Zelensky)
}

\author{
Andika Hendra Mustaqim \\ Fakultas Komunikasi dan Bahasa Universitas Bina Sarana Informatika (UBSI) Jakarta \\ Email: andika.ahq@bsi.ac.id
}

\section{Kata kunci}

Politik Selebriti, Komunikasi Politik, Voloymyr Zeleskiy
Keywords

Celebrity Politics,

Political

Communication, Voloymyr Zeleskiy

\begin{abstract}
Abstrak
Penelitian ini bertujuan untuk mengkaji secara mendalam tentang politik selebriti sebagai bagian dari komunikasi politik yang dilakukan kandidat presiden Ukraina Volodymyr Zelensky yang memenangkan pemilu pada 2019 dalam dua putaran. Paradigma penelitian ini adalah konstruktivis kritis dengan metode penelitian studi kasus berdasarkan pidato dan pernyataan politik Zelensky di media massa. Hasil analisis dan diskusi menunjukkan status selebriti Zelensky yang populer merupakan daya jual utama bagi Zelensky dan memperkuat posisinya, menggunakan pendekatan gaya komunikasi politik yang melawan hegemoni media massa, memaksimalkan peran media sosial, tidak menghadiri acara talk show, dan tidak menghadiri debat publik. Itu menunjukkan penawaran suatu pendekatan yang sebenarnya perlawanan terhadap sistem dengan rapi dan konstruktif, tetapi destruktif. Namun, berbagai program kebijakan yang ditawarkan Zelensky justru tidak berani melawan mainstream, tetap justru mengikuti arus, seperti mendukung keanggotaan Uni Eropa dan NATO, melawan Rusia, dan memperkuat perekonomian Ukraina. Kebijakan populer yang berbeda dari Zelensky adalah upayanya untuk melegalisasi ganja, prostitusi dan judi di kota tertentu.
\end{abstract}

\begin{abstract}
This study aims to examine in depth about celebrity politics as part of political communication by Ukrainian presidential candidate Volodymyr Zelenskiy who won the election in 2019 in two rounds. The paradigm of this research is critical constructivist with the case study research method based on Zelensky's speeches and political statements in the mass media. The results of the analysis and discussion showed that Zelensky's popular celebrity status was Zelensky's main selling power and strengthened his position, used a political communication style approach that opposed mass media hegemony, maximized the role of social media, did not attend talk shows, and did not attend public debates. It shows the offer of an approach that actually challenges the system neatly and constructively, but destructively. However, the various policy programs offered by Zelensky actually did not dare to fight the mainstream, they still followed the flow, such as supporting EU and NATO membership, fighting Russia, and strengthening the Ukrainian economy. A popular policy that is different from Zelensky is its efforts to legalize marijuana, prostitution and gambling in certain cities.
\end{abstract}




\section{Pendahuluan}

Politik dan selebriti bukan hal baru. Sejak Ronald Reagan terpilih sebagai Presiden Amerika Serikat (AS) pada 1981-1989, politik selebriti menjadi tren. Dia merupakan aktor Hollywood yang membangun karier politik dengan menjadi Gubernur California pada 19671975. Masih di Amerika Serikat, selebriti yang terjun ke politik adalah Arnold Schwarzenegger yang menjadi Gubernur California pada 2004-2011.

Pertengahan April lalu, dunia internasional dikejutkan dengan kehadiran Volodymyr Zelensky yang terpilih menjadi Presiden Ukraina pada pemilu presiden yang digelar 21 April 2019. Menariknya, dia adalah seorang komedian yang berperan sebagai presiden Ukraina dalam serial komedi berjudul Servant of the People. Publik pun seolah tidak percaya ketika seorang komedian berhasil memenangkan pemilu di Ukraina, negara menjadi titik konflik antara NATO (Pakta Pertahanan Atlantik Utara) dengan Rusia.

Hadirnya Zelensky menunjukkan politik selebriti masih hidup dan terus hidup. Bukan saja politik yang memanfaatkan strategi selebriti untuk meraih dukungan publik, tetapi politik yang secara murni memang mengandalkan selebriti. Para selebriti masih memiliki daya tawar yang kuat untuk memberikan gebrakan perubahan karena mereka dikenal publik sebagai figur dan masyarakat merasa dekat dengan mereka.

Aktivitas politik kini semakin populer dengan keterlibatan selebriti sebagai bentuk perayaan demokratisasi masyarakat sipil yang didukung oleh teknologi komunikasi dan informasi (Biccum, 2011), akhirnya aktivitas selebriti memang berdampak terhadap hasil politik (Wheeler, 2012), karena pengaruh perebutan suara elektoral. Peningkatan keterlibatan selebriti sangat dirasakan untuk meningkatkan sudut pandang mereka untuk meningkatkan hubungan positif (Becker, 2013), itu juga didukung oleh perkembangan media hiburan dan budaya populer yang semakin inklusif, demokratisasi, dan berpengaruh dalam kebijakan publik (Loader, Vromen, dan Xenos, 2015).

Zelensky merupakan produk dari budaya populer. Namanya sudah dikenal publik Ukraina sejak dia membintangi sejumlah film, namanya semakin melejit ketika dia memerankan peran sebagai seorang guru yang menjadi presiden Ukraina pada serial Servant of the People. Serial satir itu memberikan hiburan yang unik dengan konteks politik dengan membangun harapan tentang pemimpin harapan rakyat yang bersih dan memberantas korupsi. Film itu berusaha menunjukkan representasi kehidupan rakyat Ukraina.

Politik selebriti dimainkan dalam komunikasi politik partai dan pembuatan kebijakan (Street, 2012) dan mendorong terjadinya perubahan sosial dan politik secara umum. Politik selebriti juga mampu mempengaruhi pemerintahan modern dan operasional demokrasi kontemporer (Marsh, Hart, dan Tindall, 2010). Penelitian tentang kharisma dan selebritas pernah dilaksanakan Hughes-Freeland (2007) yang mengaitkan konsep kharisma dan selebritas modern versi Weber dengan kekuatan antropologi serta modernisasi.

Selebriti dan politik, menurut McKernan (2011), bukan hal baru, maklum politikus sudah terbiasa menggunakan elemen dramaturgi untuk memobilisasi konstituennya. Hadirnya selebritas menjadi politikus tidak lepas merupakan produk posmodernisme di tengah perkembangan hiburan dan konsumerisme di masyarakat modern (Schultz, 2016).

Politik selebriti memang melanda banyak negara, mulai dari Amerika Serikat hingga Inggris, termasuk juga di Asia. Politik selebriti juga melanda Filipina di mana banyak selebriti 
yang bertarung di parlemen dan menang (David dan Atun, 2015), padahal mereka memiliki pengalaman yang sedikit dalam kehidupan politik dan pendidikan yang rendah. Di Brazil, Ribke (2014)mengungkapkan banyak selebriti hijrah ke dunia politik di mana adanya pola interaksi antara media hiburan dengan proses demokrasi.

Bukan hanya selebriti sebenarnya yang menggunakan politik selebriti. Tapi, itu menjadi pendekatan yang digunakan politikus atau kandidat yang menggunakan elemen selebritas untuk membangun klaim untuk mewakili kelompoknya juga merupakan bentuk politikus selebritis (Street, 2004).

Wheeler (2012) melihat bukan hanya selebriti yang menggeber politik selebriti, tetapi banyak politikus yang juga menerapkan politik tersebut, seperti Barack Obama dengan menggunakan bentuk "likuid" selebriti pada kampanye pemilu 2008. Selain itu, Dalam kajian yang dilaksanakan Zoonen (2006) juga melihat dua pemimpin perempuan Eropa yakni Tarja Halonen (Finlandia) dan Angela Merkel (Jerman) melaksanakan politik selebritas yang melekat pada popularisasi dan personalisasi. Dalam analisis Zoonen menunjukkan kedua pemimpin itu menghadirkan persona politik kepada publik dengan mengungkap kehidupan pribadi mereka. Muir (2005) menyebut bahwa PM Blair dan mantan Presiden Bill Clinton merupakan politikus yang ahli dalam politik selebriti karena menawarkan personalisasi untuk menarik perhatian media dan menganggap mereka bukan politikus 'serius'.

Namun demikian, Zelensky menjadi suatu fenomena unik dalam selebritas politik karena dia sendiri berusaha melepaskan politik selebriti yang umumnya digunakan oleh politikus yang sebenarnya bukan selebriti, seperti berlebihan tampil di media, mengumbar ruang privat di depan publik, hingga menggunakan dramaturgi berlebihan untuk menarik simpati. Tidak demikian dengan Zelensky. Dia tampil berbeda dengan melawan sistem komunikasi politik yang sudah lazim. Dia ingin mencoba tampil sebagai politikus yang apa adanya, tanpa banyak polesan. Hal itu sangat wajar sebenarnya karena dia adalah selebriti yang memang sudah membangun citra sejak dia tampil di televisi.

Berdasarkan latar belakang dan permasalahan tersebut, penelitian ini bertujuan untuk mengeksplorasi tentang gaya komunikasi politik yang dijalankan Zelensky dalam pemilu presiden 2019 di Ukraina. Itu dikaitkan dengan bagaimana model dan strategi gaya komunikasi politik Zelensky. Selain itu, komunikasi politik juga bersentuhan dengan berbagai program yang dijual Zelensky untuk mendapatkan dukungan publik Ukraina.

\section{Metode}

Penelitian ini menggunakan paradigma konstruktivis kritis dengan metode penelitan studi kasus. Studi kasus dipahami sebagai kajian intensif terhadap kasus tunggal dengan tujuan untuk memberikan penerangan terhadap kelas kasus yang lebih luas (Gerring, 2006). Studi ini menggunakan metode penelitian studi kasus berbasis analisis multimodal terhadap situs internet berisi informasi politik yang mengeksplorasi dan mensistematisasi mekanisme pembuatan makna visual-verbal (Seizov, 2014).

Dipilihnya studi kasus karena penelitian fokus pada kajian komunikasi politik dengan basis kasus tertentu yang spesifik. Penelitian fokus pada studi kasus berdasarkan kajian dokumen. Hancock (2006) memaparkan kalau studi kasus juga bisa mengkaji dokumen yang 
dikumpulkan dari berbagai informasi yang valid di internet dengan memperhatikan kualitas dan reliabilitasnya.

Kemudian, dalam menganalisis data, penulis menggunakan pijakan analisis yang dikemukakan Miles dan Huberman (1994) dalam Yin (2002) meliputi peletakan informasi dalam beberapa jalur, membuat matrik kategori dan menempatkan bukti dengan kategori tersebut, menciptakan pemaparan data, menabulasi frekuensi peristiwa yang berbeda, menguji kompleksitas, dan meletakkan informasi sesuai dengan skema waktu dan kronologis. Diharapkan dengan model analisis tersebut bisa mengkaji lebih detail tentang kasus politik selebriti pada kasus Zelensky.

\section{Hasil dan Pembahasan}

Bagian hasil dan pembahasan mengungkap tentang strategi komunikasi politik yang dilakukan Zelensky dengan penjabaran berdasarkan informasi di media Ukraina dan media internasional. Kajian bersifat deskriptif, eksplanatif, dan interpretatif berdasarkan data tersebut dibalut dengan kajian teoritis dari buku dan jurnal ilmiah.

\section{Bintang Memikat}

Zelensky merupakan aktor dan direktur seni Kvartal 95, sebuah studio dan production house (Kvarta195, 2019). Dideskripsikan dalam situs tersebut bahwa Zelensky merupakan pemimpin studio Kvartal 95 yang bertugas sebagai sutradara seni, inspirator ide, dan dan penggerak tim. Dia merupakan aktor dan penulis yang telah berkarya dalam satu dekade terakhir dan menjadi salah satu selebriti paling populer di Ukraina. Dia sudah memainkan peran dalam beberapa film, seperti Love in the Big City (2009), Office Romance Our Time (2011), Love in the Big City 2 (2012), Rzhevsky Versus Napoleon (2012), 8 First Date (2012), Love in Vegas (2012), dan 8 New Dates (2012). Serial televisi yang dibintangingnya adalah Servant of the People (2015-2019) dan Dancing with the Stars (2006).

Zelensky merupakan bintang yang populer di Ukraina melalui Servant of the People. Dia dikenal sebagai aktor watak yang selalu menjiwai dalam perannya. Namanya populer semenjak dia membintangi serial yang berperan sebagai mantan guru yang menjadi presiden. Serial tersebut sebenarnya adalah sebuah film satir. Itu seperti sebagai film serial yang merepresentasikan kondisi sosial dan realitas di masyarakat Ukraina. Sebagai produser dan pemeran utama serial tersebut, Zelensky menjadi sorotan dan dia menjadi harapan baru bagi sebagian warga Ukraina yang tumbuh di media televisi.

Semuanya didasari karena keingan orang ingin hidup normal...Permasalahan korupsi menjadi permasalahan dari zaman Soviet dan orang yang berkuasa saat ini adalah dari generasi tersebut. Rakyat Ukraina ingin perubahan positif yang bisa melihat dalam karakter pertunjukan kita... Itu bukan hanya komedi, tetapi komedi politik yang mengandung satir dan drama. Itu sangat terbaru yang merefleksikan sentimen rakyat. Saya pikir itulah yang membuat populer (Volodymyr Zelensky, dalam wawancara dengan Anthony Kao, 2017, 17 Agustus).

Segala bentuk kekecewaan rakyat Ukraina terhadap isu kemiskinan, pengangguran, dan korupsi diluapkan kepada serial tersebut. Serial tersebut juga menghadirkan seorang 
pemimpin yang mau melayani dan berjuang untuk rakyat. Film serial itu membangun harapan baru bagi rakyat Ukraina dengan sosok pemimpin ideal bagi mereka.

Volodymyr Zelensky dalam wawancara dengan Anthony Kao menyatakan bahwa Kvartal 95 dan dia menerima banyak pesan dari rakyat tentang menjadikan seseorang seperti Presiden Goloborodko, untuk memimpin Ukraina guna menyelesaikan realitas dan permasalahan yang ada. Itu menunjukkan kalau tidak ada yang tidak disengaja dalam kegiatan seni, termasuk produksi serial tersebut. Bisa jadi, memang memiliki agenda utama politik dengan memproduksi film tersebut. Bukan hanya sekadar mengkritik, tetapi Zelensky memiliki motif jangka panjang.

Menurut Anthony Kao (2017, 6 Juni), Servant of the People merupakan salah satu media untuk belajar tentang Ukraina di mana korupsi terjadi di segala dimensi pemerintahan. Dia mengungkapkan yang membuat lucu satir tersebut dibandingkan komedi Barat adalah premis lelucon berdasarkan realitas. Dia juga mengungkapkan serial itu membantu masyarakat Ukraina berpikir tentang dunia alternatif di mana mereka bisa tertawa dan bermimpi mengenai hal itu.

Dalam pandangan Street (2004), selebritas atau bintang budaya populer menggunakan popularitas untuk berbicara mengenai opini populer. Itu berkaitan dengan representasi politik. Namun Street (2004) tetap berpandangan bahwa itu tidak bisa diklaim sebagai hal yang memiliki legitimasi.

Selebritas merupakan salah satu fitur dari masyarakat kontemporer yang menghadirkan kesan lintas sektoral (Kurzman et al., 2007). Mereka menganggap kalau selebriti memiliki status "terhormat", menghadirkan keuntungan ekonomi dan memiliki privasi hukum yang pasti. Hadirnya selebritas merupakan bentuk tumbuhnya kapitalisme yang terus berkembang. Menurut Kurzman et al. (2007) itu merupakan status kontemporer.

Selebriti juga bisa menjadi advokasi untuk menaikkan standar tentang bagaimana menghasilkan perhatian publik melalui berita di ranah politik (Thrall et al., 2008). Mereka juga menganggap selebritas menjadi alat dan strategi dalam politik. Itu didukung dengan evolusi teknologi digital dan ruang publik.

McKernan (2011) menyatakan kehadiran selebriti dalam politik mempengaruhi wacana politik yang serius dan itu berdampak pada penarikan publik untuk berpartisipasi lebih luas dalam politik. West (2005) menyebutkan terdapat sejumlah faktor yang menyebabkan munculnya politik selebriti. Pertama, industri media yang sangat kompetitif sehingga resporter perlu menampilkan berita yang baik dan sedikit narasumber sehingga memunculkan aktor, atlet, dan penghibur. Kedua, tidak ada batasnya antara politik dan hiburan sehingga politikus menggunakan selebriti, demikian juga sebaliknya. Ketiga, banyak pemimpin yang memiliki riwayat dari keluarga selebriti. Keempat, banyak penulis yang membahas politik selebriti dari dahulu.

\section{Melawan Hegemoni Media Massa}

Tidak seperti kebanyakan politikus di berbagai belahan dunia, Zelensky menolak kehadiran jurnalis dari berbagai media dalam rombongan kampanye. Hal itu sangat berbeda dengan kebanyakan kandidat pemimpin dan politikus yang kerap mengajak jurnalis dalam rombongan kampanye. 
Dia merasa lebih nyaman dan tenang tanpa kehadiran jurnalis. Zelensky bisa bergerak dan berbicara sesuai keinginanannya tanpa memandang ada jurnalis yang mengintai omongan dan mengawasi gerak-geriknya. Dia juga bisa ĺeluasa menjalankan strategi kampanyenya tanpa ada pihak yang bisa membocorkannya kepada publik.

Zelensky bisa jadi berpandangan sinis terhadap media massa. Sinisme memang bukan hanya melanda publik yang sudah enggan lagi percaya terhadap media, tetapi sinisme muncul dari kalangan politikus anti-kemapanan. Mereka sudah jengah dengan media yang tidak lagi objektif dan independen dalam pemberitaan dan kebijakan editorialnya.

Jelas, sikap Zelensky merupakan sikap sepihak. Dia menganggap dirinya sudah tidak lagi membutuhkan media massa. Dia menganggap media massa juga sudah tidak lagi dibutuhkan publik. Sikap seperti itu menuntun dia untuk memikiki sikap antipati terhadap media. Bahkan, dia menutup sebagian akses media kepadanya.

Praduga yang dimainkan Zelensky bahwa sebagian media massa sudah dikuasai kubu petahana. Dia pun berpikir kalau dia melibatkan jurnalis akan menghasilkan citra buruk terhadapnya karena media sudah memiliki sikap partisan. Dia pun memilih untuk menghindari jurnalis. Lebih baik tidak dikritik dibandingkan dikritik terus menerus yang akan berujung pada penurunan popularitas. Semuanya sudah dihitung dengan maksimal oleh Zelensky.

Klaim bahwa Zelensky sudah populer bisa jadi memperkuat sikapnya menghindari jurnalis dan media. Dia adalah komedian yang sudah dikenal publik secara luas. Dia juga sudah menjadi tokoh publik yang telah mengakar pada masyarakat Ukraina. Wajahnya mudah dikenali dan namanya pun sudah sudah tidak asing. Dengan begitu, dia bersikap untuk menghindari jurnalis dan tak perlu lagi publisitas.

Menghindari jurnalis juga bisa menjadi eksperimen politik yang dijalankan Zelensky. Dia beranggapan jurnalis dan media massa bukan saja menjadi benalu, tetapi batu karang yang sulit diterjang. Dia ingin menghindari benalu dan batu karang tersebut sebagai bentuk eksperimen. Dia berpikir jika eksperimennya berhasil, dia akan menjadi pemenang. Jika gagal, maka tidak ada yang dirugikan bagi dirinya.

Ternyata pemenangnya adalah Zelensky. Dengan menghindari jurnalis, suaranya justru makin meroket. Popularitasnya terus naik. Dia pun memenangkan pemungutan suara pada periode pertama dan kedua. Dia pun menjadi presiden terpilih.

Sekitar 20 media menyerukan Zelensky untuk menghentikan aksinya menghindari media (Al Jazeera, 17 April 2019). Mereka mengkritisi Zelensky agar membuktikan prinsip keterbukaan dan transparansi. Mereka mengklaim tugas profesional jurnalis untuk menghadirkan informasi ke publik tepat waktu dan komprehensif tidak berjalan dengan baik karena pengabaikan Zelensky terhadap wawancara dari media (Al Jazeera, 17 April 2019).

Media massa hanya menjadikan politik menjadi infotainment atau bisnis pertujukan (Patterson 1994; Dahlgren 1995), bahkan televisi termasuk pemberitaan hanya cenderung menghibur (Postman, 1985), berita politik dan komentar di media massa pun tak lagi serius (Franklin, 1994, Wober 1992, MacArthur \& Worcester 1992). Bahkan, media massa bisa cenderung mengemas politikus dibandingkan menyampaikan konten (Maarek 1995; D.K. Davis 1995), mengubah berita tentang partai poitik atau kebijakan pemerintahan menjadi 
berita tentang personalitas politisi yang berakibat publik tidak lagi memiliki hubungan kuat dengan partai politik (Wattenberg 1984; Fiorina 1980; Pfetsch 1996).

Sebuah kajian di India, menurut Mukjerjee (2004) menyebutkan hubungan selebriti dan politik berkaitan dengan perkembangan media massa karena politikus mengikuti perubahan dan mengikuti pasar yang berubah dan mengglobal serta peranan media dalam demokrasi. Politik selebritas awalnya hadir karena perkembangan media massa modern seperti koran, bioskop, radio dan televisi (Drake dan Miah, 2010).

\section{Memaksimalkan Media Sosial}

Media sosial, terutama YouTube dan Facebook, menjadi kekuatan utama dalam kemenangan Zelensky. Itu benar-benar disadari kalau media sosial menjadi kekuatan yang superampuh untuk mengendalikan opini publik di Ukraina. Tren itu sebenarnya telah berkembang di banyak negara, itulah yang disadari oleh Zelensky untuk mengambil kesempatan tersebut dan mengefektifkannya untuk menggaet dukungan.

Tim media digital Zelensky dipimpin oleh Mikhail Fedorov (The Atlantic, 17 April 2019). Dijelaskannya, lawan utama tim kampanye media sosial bukan saja dari lawan politik, tetapi akun boot dan banyak akun palsu yang menyebarkan informasi yang tidak benar. Dia pun meminta bantuan Facebook dan Google mengenai konten yang tidak benar (The Atlantic, 17 April 2019).

Seperti kebanyakan politikus antikemapanan, Zelensky menggunakan media sosial sebagai kekuatan utamanya untuk menyampaikan pendapat dan menyuarakan dengan lantang tanpa mempedulikan ada pihak yang mengedit atau mempengaruhinya. Dia tampil menjadi pribadi yang apa adanya dengan media sosial yang sudah semakin populer dan diakses oleh banyak orang, termasuk di Ukraina. Kampanye melalui media sosial juga lebih murah sehingga menjadi pilihan paling masuk akal bagi para politikus baru, termasuk Zelensky. Berbeda dengan iklan di televisi atau media cetak yang membutuhkan biaya besar, media sosial lebih murah bahkan bisa dikatakan gratis.

Biaya diperlukan untuk merekrut relawan dan pegawai untuk mengelola akun media sosial. Namun, biaya itu tidak sebesar biaya iklan di media cetak atau televisi. Dengan pengorganisasian berbasis relawan, maka efektivitas dan efisiensi akan menjadi lebih baik karena manajemen berbasis pada gotong royong bukan pada sistem produksi pasar.

Media sosial juga menjadi strategi kampanye yang efektif untuk menjangkau anak muda yang mayoritas pemilih pemula. Mereka adalah generasi yang akrab dengan media sosial. Mereka juga percaya dengan informasi yang tersedia di media sosial. Apalagi figur Zelensky yang masih relatif lebih muda dibandingkan kandidat petahana menjadi daya tarik sendiri.

Lalancette dan Raynalud (2017) menyatakan penggunaan media sosial untuk mendapatkan perhatian melalui citra yang berdampak atau video setiap hari telah menjadi norma. Itu merupakan bentuk dari manajemen citra untuk menciptakan kesan bahwa politikus memiliki kualitas.

Politikus dan selebritas, dalam pandangan McKernan (2011) memiliki kesamaan yakni keduanya membangun personalitas publik untuk penonton mereka dan menerapkan mirip aktor serta strategi untuk membantu menciptakan personalitas tersebut. Citra memainkan peranan penting dalam politik untuk berkaitan dengan politik (Lalancette dan Raynalud, 
2017), untuk mencari kualitas tertentu pada pemimpin politik, seperti kejujuran, inteligensi, persahabatan, kejujuran, dan kepercayaan untuk membuat keputusan elektoral.

Tren penggunaan media sosial, seperti Facebook dan Twitter, membuat banyak politikus dan pegiat hiburan menjalin hubungan dengan masyarakat sehingga mengembangkan politik selebritas (Loader et al., 2015). Hasil penelitian mereka menemukan kalau media sosial mampu menciptakan hubungan yang positif antara selebritas dan politikus dalam membangun hubungan ulang kepercayaan dan kredibilitas. Ditambah dengan kehadiran teknologi komunikasi digital dan internet yng mendukung selebriti tampil ke publik dalam 100 tahun terakhir, juga mendorong selebriti menjadi komoditas (Drake dan Miah, 2010) yang didorong juga oleh media yang multi kanal.

Seperti penelitian tentang Justin Trudeau, Perdana Menteri Kanada, oleh Lalancette dan Raynalud (2017), menunjukkan bahwa penggunaan Instagram Trudeau bertujuan untuk membangun citra di depan pemilih dengan konteks permanen dan meningkatkan kampanye personalisasi, serta bagaimana dia menggunakan Instagram untuk mendukung nilai dan ide Partai Liberal dan mendiskusikan isu lingkungan, pemuda, dan teknologi.

\section{Menolak Skenario Program Hiburan untuk Politik}

Sudah menjadi hal lumrah dalam dunia komunikasi politik kalau talk show atau acara dialog di televisi menjadi ajang untuk mempromosikan diri bagi kandidat pemimpin atau politikus kepada publik. Banyak pula politikus memanfaatkan acara tersebut dengan membeli jam tayang. Acara dialog atau talk show pun menjadi ajang tanya jawab yang sudah diskenariokan.

Di era posmodernisme, politik hanya menjadi seperti hiperealitas dan simulacra. Politik itu bisa menghipnotis penonton televisi untuk bisa percaya dengan program dan kinerja mereka. Namun, politik juga bisa mempermainkan imajinasi layaknya sebuah tontonan yang menghibur. Itu semua bertujuan untuk memberikan pengaruh dan menghegemoni para pemirsa untuk memberikan dukungan, minimal memberikan simpati.

Itulah yang ingin dihindari oleh Zelensky. Dia tidak ingin mengikuti politik arus utama yang berkembang di Ukraina dan berbagai belahan dunia. Dia ingin tampil beda, mengandalkan kemampuannya dalam kampanye pemilu. Dia juga ingin membuktikan siapa yang terbukti efektif dan efisien. Dengan tidak mengandalkan berbagai program televisi, Zelensky justru lebih mengena dengan target elektoral yang hendak dibidiknya. Dia tidak mempedulikan pandangan miring dirinya jarang tampil di program televisi dalam berita atau pun dialog, karena dia telah memiliki target yang lebih aktif dan lebih pasti dalam memberikan dukungan.

Zelensky tidak mengandalkan program televisi karena dirinya juga sudah populer. Dia tidak perlu lagi menyapa publik yang telah mengenalnya. Dia telah menjadi bagian yang tidak dilepaskan dari tayangan program serial televisi yang dibintanginya. Dia sudah menjadi magnet yang ditonton banyak orang Ukraina.

Pada umumnya, berbagai program televisi menjadi ajang bagi politikus untuk tampil menunjukkan diri kepada publik. Itu menjadi hal menarik karena program itu memiliki banyak loyalis yang menonton. Itu bertujuan untuk menambah popularitas. Tampil di berbagai program tersebut juga mampu menjalin hubungan untuk membentuk politik 
representasi yang tepat. Seperti yang dialami George Galloway tampil dalam Celebrity Big Brother, sebagai program reality show, untuk membangun kedekatan dengan konstituennya pada 2006 (Cardo, 2013). Cardo menyatakan kalau program televisi mampu mengartikulasikan ide dan nilai politik.

\section{Menolak Debat Publik}

Debat merupakan ajang untuk menunjukkan kemampuan seorang kandidat pemimpin untuk menyampaikan program dan kemampuan retorikanya. Seorang calon pemimpin biasanya akan menunjukkan siapa dirinya dalam debat. Publik pun akan memberikan penilaian. Tapi, Zelensky memilih tidak untuk mengikuti debat. Dia tidak menghadiri debat yang sebenarnya dihadiri oleh lawan politiknya. Itu merupakan klimaks dari perlawanan terhadap sistem politik yang sebenarnya sudah terbangun sejak lama, bukan hanya di Ukraina, tetapi di banyak negara.

Zelensky tidak menghadiri debat yang sudah disepakati sebelumnya dengan Presiden petahana Petro Poroshenko (BBC.com, 14 April 2019). Akhirnya, Poroshenko hanya berpidato sendiri di depan ribuan orang yang sudah hadir di Stadion Olimpiade Kiev. Pada kesempatan itu, Poroshenko mengkritik Zelensky khawatir dan bersembunyi dari masyarakat (BBC.com, 14 April 2019).

Perlawanan dengan tidak mengikuti debat menunjukkan suatu risiko yang sangat besar bagi Zelensky. Namun, itu tetap dijalani dengan segala risikonya. Dia ingin menunjukkan kalau debat bukan sebagai cara terbaik untuk mencari seorang pemimpin. Dia ingin mengonstruksi pesan bahwa debat adalah cara yang menyesatkan untuk memilih pemimpin.

Zelensky menolak debat yang hanya dijadikan sebagai ajang pentas drama. Dia menolak politik pertunjukan, meskipun dirinya adalah aktor yang terbiasa akting. Dia tetap menganggap kalau debat bukan sebagai cara terbaik untuk menilai pemimpin karena sama seperti bersandiwara.

\section{Memerangi Gerakan Anti-Politik}

Gerakan anti-politik yang paling nyata ditunjukkan dengan golput (golongan putih). Mereka terang-terangan tidak memberikan suara dan tidak datang ke tempat pemungutan suara. Itu sebagai bentuk kekecewaan terhadap warga yang sudah bosan dan tidak suka dengan politik. Mereka beranggapan politik tidak lagi memberikan harapan dan solusi bagi permasalahan kehidupan berbangsa dan bernegara. Mereka pun marah dengan kondisi banyak politikus yang korup dan hanya memperkaya diri sendiri. Fenomena itu terjadi di Ukraina.

Zelensky menggelorakan nuansa anti-politik yang berjanji melakukan perubahan (Dejevsky, 201918 April), dengan target utama adalah pemilih pemula. Menurut Dejevsky, Zelensky bangkit di era anti-politik yang memberikan kemenangan baginya. Kehadiran Zelensky memberikan harapan baru, terutama di kalangan generasi muda, untuk kembali aktif pada politik dan peduli dengan apa yang terjadi dengan negara. Zelensky memberikan janji perubahan menjadi senjata utama untuk melawan gerakan anti-politik.

Syarat utama untuk melawan fenomena anti-politik adalah memunculkan figur baru. Zelensky dianggap tepat sebagai figur baru yang bersih dari sentuhan politik rezim 
sebelumnya. Dia tampil sebagai figur yang segar yang menawarkan sesuatu yang baru yang tidak ditawarkan rezim sebelumnya.

Selain figur baru, anti-politik juga bisa ditawarkan dengan memberikan gebrakan yang melawan sistem. Itu dilakukan oleh Zelensky dengan membedakan dirinya dengan politikus lama dalam berbagai strategi komunikasi politik yang dilakukan. Dengan diferensiasi yang telah dilakukan Zelensky, citra sebagai politikus yang berbeda akan melekat padanya.

Politikus yang mengadopsi gaya politik selebritas dan kehadiran selebriti menjadi politikus ternyata menjadi solusi di era anti-politik (Wood et al., 2016). Itu seiring dengan interplay antara budaya selebritis dan strategi presentasi yang diadopsi banyak politikus. Mereka membagi dua kategori yakni potikus selebriti superstar dan politisi selebritis setiap hari yang menampilkan teknik marketing dan peranan performatif (Wood et al., 2016). Menurut Wood et al. (2016), politikus selebriti juga memiliki tujuan untuk meningkatkan popularitas dan kredibilitas di abad anti-politik.

Anti-politik juga berkaitan dengan kapitalisme (Eyal, 2000), liberalisme yang berakibat ketidakperbihakan terhadap rakyat miskin juga memicu anti-politik (Hickey, 2009). Antipolitik juga sebagai gerakan yang bermanuver untuk mendapatkan legitimasi dan dukungan (Buscher, 2010). Gerakan anti-politik tidak lelpas dari berbagai petunjukan operasi sabun yang timbul di publik terhadap institusi politik dan politik sendiri yang disebabkan ketidakpercayaan terhadap politisi dan institusi politik yang berujung pada sinisme (Fieschi dan Heywood, 2014).

\section{Zelensky Hanya Boneka?}

Zelensky dituding hanya menjadi boneka. Dia hanya menjadi kepanjangan tangan dari orang dan kelompok tertentu yang memiliki keinginan tertentu. Itu menunjukkan kalau Zelensky tidak murni menjadi dirinya sendiri. Namun, dia tetap seorang aktor. Hanya saja, dia menjadi aktor di panggung politik yang sebenarnya, bukan pada sebuah komedi satir.

Orang yang di belakang Zelensky merupakan lawan utama petahana. Zelensky hanya dipinjam untuk melawan kepentingan yang lebih besar. Dia menjadi alat untuk mengamankan kepentingan dan kekuasaan.

Sejak awal pertarungan pemilu dimulai, Volodymyr Zelensky dianggap sebagai perwakilan Ihor Kolomoisky - seorang miliarder, pemilik stasiun televisi di mana Zelensky bekerja, dan mantan gubernur wilayah Dnipropetrovsk. Setelah mengundurkan diri dari gubernur dan nasionalisasi bank terbesar di Ukraina, PrivatBank, yang dimiliki Kolomoisky, kini dia tinggal di luar Ukraina yakni di Swiss dan Israel dan musuh petahana Presiden Poroshenko. Dengan perubahan kepemimpinan di Ukraina akan menguntungkannya (Volnsky, 2018, 17 April).

Laporan Reuters (2019, 22 April) mengungkap hubungan antara Zelensky dengan Andrei Bogdan, seorang pengacara Ukraina, yang diungkap media lokal Ukraina memiliki kedekatan dengan Kolomoisky. Selain itu, Zelensky juga dekat dengan Timur Mindych yang juga memiliki hubungan bisnis dengan taipan Kolomoisky.

Hal itu sangat disadari oleh Zelensky. Itulah kenapa dia memilih jalan yang berbeda dan melawan sistem dengan gayanya sendiri. Menjadi boneka dalam panggung politik sudah menjadi hal biasa. Banyak kandidat hanya menjadi pion yang bertempur. Mereka 
dikendalikan oleh pihak tertentu untuk berkuasa. Namun, setelah berkuasa, politikus boneka itu hanya menjadi alat bagi kepentingan tertentu.

Hanya saja, Zelensky berbeda. Dia berangkat dari aktor yang memainkan peranan sebagai presiden. Dia memiliki beban dan harapan di pundaknya. Publik akan menilai Zelensky menjadikan pemerintahan Ukraina ke depan menjadi menarik.

\section{Mewujudkan Kedekatan dengan Uni Eropa dan NATO}

Dalam beberapa kesempatan, Zelensky berulang kali mengungkapkan dirinya akan menjadikan Ukraina menjadi anggota Uni Eropa dan NATO (Pakta Pertahanan Atlantik Utara). Itu menunjukkan kalau dia bukan antek Rusia. Itu juga tidak berbeda dengan kebijakan yang ditempuh oleh pemimpin sebelumnya, Poroshenko yang berpihak kepada Uni Eropa dan NATO.

Zelensky juga sudah mengetahui suara mayoritas warga Ukraina yang ingin lebih dekat dengan Uni Eropa dibandingkan Rusia. Akses ekonomi ke Uni Eropa dianggap lebih menjanjikan dibandingkan berpihak kepada Rusia. Sentimen anti-Rusia juga dimainkan Zelensky selama kampanye. Dia kerap mengejek Rusia dan melontarkan bahan candaan kepada Presiden Vladimir Putin. Dengan gaya yang tetap mengutamakan satir, dia ingin menunjukkan posisinya kepada rakyat Ukraina bahwa dirinya tetap bersama Uni Eropa.

Zelensky tidak akan mengubah jalur menuju keanggotaan Uni Eropa dan NATO. Dalam wawancara dengan stasiun televisi Ukraine, dia mengungkapkan Ukraina telah menentukan langkah integrasi euro dan bergerak menuju Eropa sejak lama dan tidak ada orang yang akan mengubah hal tersebut (uawire.org, 2019, 8 April). Dia juga menambahkan bahwa dirinya tetap condong ke arah NATO untuk menjamin keamanan negaranya. Dia berjanji akan melaksanakan referendum nasional untuk menentukan bergabung dengan NATO (uawire.org, 2019, 8 April).

Memilih mendekati Uni Eropa dan NATO menjadi pilihan paling pragmatis dan rasional. Zelensky berpikir tentang masa depan Ukraina yang lebih baik berada di dekat Uni Eropa dibandingkan dengan Rusia. Dia sudah menghitung kalkulasi kalau Uni Eropa akan mendapatkan banyak dukungan dari anggotanya, sedangkan Rusia hanya memiliki sedikit aliansi.

Selama ini, pendekatan yang dilakukan Uni Eropa dan NATO kepada Ukraina juga sudah berjalan. Mereka sudah mengirimkan bantuan ekonomi dan tentara untuk melatih tentara Ukraina. Pendekatan ekonomi dan keamanan Uni Eropa dan NATO itu lebih mengena bagi Ukraina dibandingkan dengan yang dilakukan Rusia. Meskipun, secara sosial, budaya, historis, dan geografis, Ukraina memiliki kedekatan dengan Rusia.

\section{Memberantas Korupsi}

Pada 6 April 2019, Zelensky memaparkan program anti-korupsi yang menjadi andalannya dengan mengutamakan perubahan sistem dan melakukan perlawanan terhadap politikus korupsi (KyivPost, 2019, 8 April). Program tersebut di antaranya memberikan jaminan terhadap lembaga anti-korupsi untuk melaksanakan tugasnya secara independen, menghabis imunitas bagi politikus, mendirikan pengadilan ekonomi tinggi, memberlakukan $e$ government dengan melaksanakan pemerintahan berbasis online, membangun kemitraan 
dengan warga untuk pemberian imbalan bagi orang yang mengungkap korupsi, bekerja sama dengan lembaga penegakan hukum di Barat, dan fokus pada dekriminalisasi ekonomi (Kyivpost, 2019, April 8).

Isu korupsi menjadi isu yang dijual oleh banyak politikus di seluruh dunia. Pasalnya, korupsi masih menjadi penyakit yang melekat pada pemerintahan negara berkembang. Beragam janji pemberantasan korupsi tak akan lekang ditelan zaman selama korupsi masih menjadi benalu dalam pemerintahan.

Di Ukraina, korupsi masih menjadi isu sentral pada kampanye pemilu presiden. Korupsi tentunya menjadi janji yang diandalkan oleh kubu penantang yakni Zelensky. Dia menuding kalau pemerintahan petahana masih melanggengkan korupsi. Pemberantasan korupsi pun dianggap tidak berhasil.

Ukraina menempati peringkat 114 indeks korupsi versi Transparancy International pada 2013 dan 120 pada 2018. Economist mencatat kalau Ukraina menyelamatkan 6 miliar dolar dengan mengeliminasi kesempatan untuk korupsi (The Ukrainian Weekly, 2019, 26 April).

Janji pemberantasan korupsi akan sangat mudah dilantunkan polikus baru yang belum masuk dalam sistem. Itu akan memperkuat citra bersih yang melekat padanya. Publik pun cenderung lebih percaya dengan figur baru dibandingkan figur lama dalam pemberantasan korupsi. Apalagi, peran Zelensky dalam serial yang mengangkat namanya, dia berperan sebagai presiden yang berjuang memberantas korupsi. Itu menambahkan predikat pemberantas korupsi pada diri Zelensky. Predikat tersebut pada kehidupan nyata yang dialaminya di dunia politik.

Dengan predikat tersebut, Zelensky mampu menghipnotis publik. Masyarakat Ukraina seolah-olah percaya dengan predikat melekat tersebut. Di era hiperalitas ini, orang cenderung mudah percaya dengan apa yang diyakini dengan atribut. Mereka tidak lagi melihat esensi yang lebih dalam dan lebih komprensif. Pola pikir logika pendek sangat bermain dalam era posmodernisme, termasuk dalam politik posmodernisme. Dengan dasar keyakinan, orang akan tunduk dan menjadi loyalis yang mati-matian berjuang untuk idolanya.

Kesempatan yang dimiliki Zelensky memang sudah dikontruksi sangat detail. Dia sudah memperkuat citra dirinya sebelum bertarung di politik. Dia mencoba eksperimen yang kuat dan valid untuk membuktikan bahwa dirinya adalah pemberantas korupsi. Publik Ukraina pun percaya.

\section{Melawan Rusia}

Pengaruh Rusia di Ukraina sangat besar. Apalagi, sebagian penduduk Ukraina masih berbahasa Rusia, terutama di Ukraina Timur. Pengaruh itu dalam bentuk ancaman atau agresi. Apalagi, Rusia juga memiliki banyak pendukung dan milisi yang masih setia di Ukraina. Ukraina juga memiliki kisah kelam dengan Rusia. Apalagi sejak militer Rusia mencaplok Crimea dari wilayah Ukraina pada Maret 2014. Itu menjadi hal penting bagi setiap pemimpin Ukraina kalau ancaman Rusia akan selalu menghantui mereka.

Namun, upaya untuk mencari "kesamaan pandangan" dengan Rusia tetap ditempuh oleh Zelensky. Itu dilakukan sebagai upaya untuk menetralisir. Dia tidak ingin berkonfrontasi langsung dengan Rusia karena risiko besar yang akan dihadapi oleh Ukraina. 
"Setelah 'selamat tinggal', 'hari baik' akan datang, tentunya. Saya berpikir tentang Ukraina dan Rusia memiliki 'banyak kesamaan'. Realitasnya adalah aneksasi Crimea dan agresi di Donbass, kita memiliki satu yang tertinggal dalam 'persamaan'- ini adalah perbatasan negara: $2.295 \mathrm{~km}$ dan 400 meter dalam 'persamaan'. Rusia seharusnya mengembalikan kontrol setiap milimeter dari sisi Ukraina. Namun, kita juga akan melanjutkan mencari 'persamaan'," demikian tulis Zelensky pada akun Facebooknya (Tass, 2019, Mei 2).

Menjauhi Rusia dianggap sebagai pilihan terbaik karena Zelensky memilih mendekati Uni Eropa dan NATO. Posisi itu akan memperkuat citra Zelensky sebagai pemimpin yang melawan Presiden Rusia Vladimir Putin, bukan sebagai kolega atau pun kroni Putin.

Sejak pecahnya Uni Soviet pada 1992, hubungan tidak harmonis atara Rusia dan Ukraina mulai merebak (Felgenhauer, 1999), kedua negara tersebut juga mengalami transformasi (Solchanyk, 1996), dan kedua negara itu masuk dalam percaturan geopolitik (Larrabee, 2010).

\section{Memperkuat Ekonomi}

Kondisi perekonomian Ukraina memburuk di bawah kepemimpinan Poroschenko. Itu menjadikan Zelensky memfokuskan kampanye pada isu ekonomi. Dia mengkritisi pemerintahan sebelumnya yang dinilai lalai karena tidak mampu membangkitkan perekonomi dalam negeri Ukraina.

Ukraina kini mengalami pertumbuhan ekonomi 2-3\% per tahun sejak 2016. Pendapatan personal tumbuh 10,9\% dan 9,9\% pada 2017 dan 2018. Inflasi mencapai $9,8 \%$ pada 2018. Buruh migran berkontribusi terhadap 14 miliar dolar terhadap ekonomi tahun lalu melalui remitan yang lebih tinggi dibandingkan investasing asing langsung. Ukraina mengekspor 20 miliar barang dan layanan jasa ke Uni Eropa tahun lalu di mana 3,7 miliar ke Rusia (The Ukrainian Weekly, 2018, 26 April).

Ekonomi itu selalu menyangkut hajat hidup orang banyak. Semua pemilih akan memilih pemimpin yang memperjuangkan ekonomi, yang berpihak kepada masyarakat dengan mengandalkan program populis. Untuk membangkitkan ekonomi, program yang dijual bertujuan menarik investasi. Itu bisa diwujudkan ketika investor asing percaya dengan pemerintahan yang memiliki legitimasi dengan jaminan pertumbuhan ekonomi yang stabil. Faktor politik dan hukum menjadi payung pendukung yang mampu menyakinkan para investor.

Investasi juga bisa hadir dengan serangkaian program yang mampu memberikan jaminan bahwa uang yang diinvestasikan akan kembali dan menguntungkan. Berbagai program seperti pemotongan pajak hingga kemudahan dalam pengurusan izin menjadi andalan utama. Dengan masuknya investasi, maka pengangguran akan berkurang. Tenaga kerja akan diserap lebih maksimal. Investasi masuk akan meningkatkan pertumbuhan ekonomi.

Pembangunan ekonomi berbasis ekonomi skala menengah juga dimainkan Zelensky. Itu disadari perekonomian skala menengah memang menjadi andalan karena sebagian besar perekonomian dunia dikendalikan oleh sektor ekonomi tersebut. Dengan begitu, suara mayoritas rakyat akan mendapatkan perhatian utama. Zelensky juga membangun dan 
mendorong kewirausahaan. Tren itu untuk menarik generasi muda yang menolak kemapanan dengan membangun bisnis skala kecil dan menengah. Janji pemberian kredit dengan bunga ringan menjadi andalan utama.

\section{Legalisasi Ganja, Prostitusi dan Judi}

Legalisasi ganja masih menjadi isu sensitif di sebagian negara di dunia. Tapi, di Barat, legalisasi ganja sudah menjadi isu yang lazim. Itu bukan untuk tujuan kesenangan, tetapi alasan medis yang menjadi dasar untuk legalisasi. Zelensky berpikir bisa menjadikan Ukraina sebagai negara tujuan wisata dengan mengandalkan legalisasi ganja. Itu menjadi kepentingan jangka pendek saja.

Ganja untuk kesehatan, saya pikir itu adalah hal normal untuk melegalisasinya. Itu akan dijual dalam bentuk kemasan. Namun, saya berkonsultasi dengan Yevhen Olehovych Komarovsky (dokter ternama Ukraina) mengenai masalah ini. Saya mendukung legalisasi ganja dalam yang dijual dalam bentuk minyak (Unian, 2019, 18 April).

Legalisasi ganja juga menunjukkan kalau Zelensky memiliki pandangan liberal. Selama ini kaum liberal sangat mendukung legalisasi ganja untuk kepentingan medis. Langkah itu juga untuk menarik simpati dan dukungan dari generasi muda Ukraina. Bagi kalangan generasi tua, kebijakan tersebut tidak akan berdampak besar.

Kemudian, prostitusi legal di Ukraina juga menjadi isu yang menarik. Prostitusi itu menjadi hal yang selama ini disembunyikan dan tidak terang-terangan. Hal itu menimbulkan dampak buruk dalam pencrgahan penyakit menular.

Seks untuk mendapatkan uang? Sejujurnya, saya pikir kita memiliki kesempatan dan saya akan menjawab permasalahan ini di sini dengan mendirikan 'Las vegas' (di Ukraina). Masyarakat tidak berpikir demikian, pajak yang akan dibayar. Kenapa tidak memberikan kesempatan untuk sebuah kota atau teritorial dan membuka itu semuanya di sana (Unian, 2019, 18 April).

Pelegalan prostitusi tidak lepas dari keinginan untuk menarik banyak wisatawan asing ke Ukraina. Zelensky membangun citra bukan politikus yang berpatokan pada etika. Dia ingin menunjukkan bahwa prostitusi bukan hanya menyangkut ekonomi perseorangan tetapi berdampak luas.

Selanjutnya, Legalisasi judi menjadi keinginan Zelensky agar Ukraina memiliki Las Vegas. Itu bisa menjadi kekuatan besar yang mampu mendorong tumbuhnya perekonomian dan menarik banyak wisatawan.

Ya, itu tentang pemberian kesempatan, dengan mengambil semuanya dan memindahkan semuanya ke kota tertentu yang melegalisasi judi. Tolong, jangan bersenang-senang di sana. Itu tidak akan menjadi wilayah tertentu. Sebagai hasilnya, ada kota yang bisa dikembangkan untuk menjadi kota seperti (Unian, 2019, 18 April).

Berbagai janji dan program legalisasi ganja, prostitusi, dan judi menjadi hal yang populer di kalangan rakyat Ukraina yang membutuhkan atmosfer pembaharuan dalam berbagai lini kebijakan yang berbeda dibandingkan pemerintahan sebelumnya. Itu sangat 
disadari Zelensky dengan membuat kebijakan populer yang nantinya memberi dampak nyata kepada pemerintahan dan rakyatnya.

\section{Simpulan}

Hasil analisis dan diskusi menunjukkan kalau Zelensky bintang yang mampu menjadi kekuatan yang bisa mendulang suara dalam pemilu presiden karena kepopulerannya sebagai bintang serial televisi Servant of People. Status selebriti yang populer merupakan daya jual utama bagi Zelensky. Popularitas adalah segalanya dalam politik dengan memperkuat posisi selebriti yang sudah dikenal untuk menarik dukungan publik.

Kemudian, Zelensky menggunakan pendekatan gaya komunikasi politik melawan hegemoni media massa dengan tidak terlalu intensif berhubungan dengan jurnalis, bahkan cenderung mengabaikannya. Tapi, Zelensky memiliki senjata baru yang ampuh yakni memaksimalkan peran media sosial dengan mengampanyekan programnya pada kanal-kanal media sosial miliknya, seperti Facebook dan YouTube. Perlawanan dengan pemberitaan televisi juga dilakukannya dengan tidak menghadiri acara talkshow yang diangap penuh skenario.

Zelenksy menolak menghadiri debat publik sebagai bentuk penolakan mengikuti sistem kampanye yang sudah ditentukan. Zelensky memosisikan dirinya sebagai figur yang menawarkan pembaharuan untuk memerangi gerakan anti-politik. Namun demikian, sebagian pihak menyatakan Zelenksy hanya sebagai "boneka" politik dari pengusaha Ihor Kolomoisky yang merupakan musuh utama dari pemimpin petahana.

Bukan sekadar kontroversi dengan menolak berbagai hal yang sudah lazim dalam komunikasi politik dan dilakukan banyak politikus di dunia, tetapi Zelensky menawarkan suatu pendekatan yang sebenarnya perlawanan terhadap sistem dengan rapi dan konstruktif, tetapi destruktif. Zelensky hanya menghindar, tetapi tidak berkoar-koar dengan menjelekkan berbagai model kampanye yang populer dengan tudingan adanya skenario, konstruksi citra, dan permainan politikus. Tetapi, dia sendiri juga sedang mengonstruksi dirinya sebagai kandidat yang berbeda dengan politik kemapanan yang sedang berkuasa.

Berbagai program kebijakan yang ditawarkan Zelensky justru tidak berani melawan mainstream, tetap justru mengikuti arus. Dia ingin terus mewujudkan Ukraina menjadi anggota Uni Eropa dan NATO. Janji pemberantasan korupsi dengan membuat kebijakan antikorupsi dan mendorong independensi lembaga anti-korupsi menjadi daya jual. Dia juga memilih bermusuhan dengan Rusia, namun tetap mengupayakan duduk dalam satu meja untuk berunding dan berdiskusi dengan Moskow. Memperkuat ekonomi sebagai janjinya dengan meningkatkan investasi.

Berbagai program yang ditawarkan tersebut tidak terlalu berbeda dengan rival utamanya. Zelensky memang tidak memiliki banyak pilihan ketika berhadapan dengan realitas politik yang tidak bisa dihindarinya dalam hal kebijakan. Itu juga tidak lepas dari sikap politik dan ekonominya yang sudah dibangunnya sejak dahulu.

Kebijakan populer yang berbeda dari Zelensky adalah upaya melegalisasi ganja, prostitusi dan judi di kota tertentu di Ukraina, untuk menarik kunjungan wisatawan dan menghidupkan ekonomi. Improvisasi kebijakan tersebut menawarkan perspektif baru untuk 
kebangkitan ekonomi dan politik Ukraina. Kebijakan tersebut juga bisa menimbulkan friksi baru di lintas sosial dan kultural yang nantinya bisa berdampak sangat nyata.

\section{Referensi}

Becker, A. B. (2013). Star power? Advocacy, receptivity, and viewpoints on celebrity involvement in issue politics. Atlantic journal of communication, 21(1), 1-16. DOI: $10.1080 / 15456870.2013 .743310$

Biccum, A. (2011). Marketing development: celebrity politics and the 'new'development advocacy. Third world quarterly, 32(7), 1331-1346. DOI: 10.1080/01436597.2011.600107

Büscher, B. (2010). Anti-politics as political strategy: Neoliberalism and transfrontier conservation in southern Africa. Development and change, 41(1), 29-51. DOI: 10.1111/j.1467-7660.2009.01621.x

Cardo, V. (2014). Celebrity politics and political representation: The case of George Galloway MP on Celebrity Big Brother. British Politics, 9(2), 146-160. DOI: doi.org/10.1057/bp.2013.22

Dahlgren, P. ( 1995). Television and the public sphere. London: Sage.

David, C. C., \& Atun, J. M. L. (2015). Celebrity Politics: Correlates of Voting for Celebrities in Philippine Presidential Elections. Social Science Diliman, Vol. 11 Issue 2, p1-23.

Davis, D.K. ( 1995). Mass and modernity: The future of journalism in a post Cold War and postmodern world. In P.C. Wasburn (ed), Research in political sociology, Volume 7: Mass media and politics. Greenwich, CT: JAI Press.

Drake, P., \& Miah, A. (2010). The cultural politics of celebrity. Cultural Politics, 6(1), 49-64. DOI: $10.2752 / 175174310 X 12549254318746$.

Eyal, G. (2000). Anti-politics and the spirit of capitalism: Dissidents, monetarists, and the Czech transition to capitalism. Theory and Society, 29(1), 49-92. DOI: 10.1023/A: 1007086330378

Felgenhauer, T. (1999). Ukraine, Russia, and the Black Sea Fleet Accords. Princeton University.

Fieschi, C., \& Heywood, P. (2004). Trust, cynicism and populist anti-politics. Journal of Political Ideologies, 9(3), 289-309. DOI: doi.org/10.1080/1356931042000263537

Fiorina, M. (1980). The decline of collective responsibility. Daedalus 109: 25- 74.

Gerring, John. (2006). Case Study Research: Principle and Practices. Cambridge: Cambridge University Press.

Hancock, Dawsown R. (2006). Doing Case Study Research: A Practical Guide for Beginning Researchers. London: Teachers College Columbia University.

Hickey, S. (2009). The politics of protecting the poorest: Moving beyond the 'anti-politics machine'?. Political Geography, 28(8), 473-483. DOI: 10.1016/j.polgeo.2009.11.003

Hughes-Freeland, F. (2007). Charisma and celebrity in Indonesian politics. Anthropological Theory, 7(2), 177-200. DOI: 10.1177/1463499607077297

Kurzman, C., Anderson, C., Key, C., Lee, Y. O., Moloney, M., Silver, A., \& Van Ryn, M. W. (2007). Celebrity status. Sociological theory, 25(4), 347-367. DOI: 10.1111/j.14679558.2007.00313.x 
Lalancette, M., \& Raynauld, V. (2017). The power of political image: Justin Trudeau, Instagram, and celebrity politics. American Behavioral Scientist, DOI: 0002764217744838.

Larrabee, F. S. (2010). Russia, Ukraine, and Central Europe: the return of geopolitics. Journal of international affairs, 63(2), 33-52.

Loader, B. D., Vromen, A., \& Xenos, M. A. (2016). Performing for the young networked citizen? Celebrity politics, social networking and the political engagement of young people. Media, culture \& society, 38(3), 400-419. DOI: 10.1177/0163443715608261

Maarek, P.J. ( 1995). Political marketing and communication. London: John Libby.

Marsh, D., Hart, P. T., \& Tindall, K. (2010). Celebrity politics: The politics of the late modernity?. Political studies review, 8(3), 322-340. DOI: 10.1111/j.14789302.2010.00215.x

McKernan, B. (2011). Politics and celebrity: a sociological understanding. Sociology Compass, 5(3), 190-202.10.1111/j.1751-9020.2011.00359.x

Muir, K., 2005. Media Darlings and Falling Stars: Celebrity and the Reporting of Political Leaders. Westminster Papers in Communication and Culture, 2(2), pp.54-71. DOI: $10.16997 /$ wpcc. 24

Mukherjee, J. (2004). Celebrity, media and politics: An Indian perspective. Parliamentary Affairs, 57(1), 80-92. DOI: 10.1093/pa/gsh007

Patterson, T.E. ( 1980). The mass media election: How Americans chose their president. New York: Praeger.

Pfetsch, B. (1996). Convergence through privatization? Changing media environments and televised politics in Germany. European Journal of Communication 8( 3): 425- 450.

Postman, N. (1985). Amusing ourselves to death: Public discourse in the age of show business. New York: Viking-Penguin Books.

Ribke, N. (2015). Entertainment politics: Brazilian celebrities' transition to politics, recent history and main patterns. Media, Culture \& Society, 37(1), 35-49. $10.1177 / 0163443714549087$

Schultz, D. (2001). Celebrity politics in a postmodern era: The case of Jesse Ventura. Public Integrity, 3(4), 363-376. DOI: 10.1080/15580989.2001.11770886

Seizov, Ognyan. (2014). Political Communication Online: Structures, Functions, and Challenges. London: Routledge.

Solchanyk, R. (1996). Ukraine, Russia, and the CIS. Harvard Ukrainian Studies, 20, 19-43.

Street, J. (2004). Celebrity politicians: popular culture and political representation. The British journal of politics and international relations, 6(4), 435-452. DOI: 10.1111/j.1467-856X.2004.00149.x

Street, J. (2012). Do celebrity politics and celebrity politicians matter?. The British journal of politics and international relations, 14(3), 346-356. DOI: 10.1111/j.1467856X.2011.00480.x

Thrall, A. T., Lollio-Fakhreddine, J., Berent, J., Donnelly, L., Herrin, W., Paquette, Z., ... \& Wyatt, A. (2008). Star power: Celebrity advocacy and the evolution of the public sphere. The international journal of press/politics, 13(4), 362-385. DOI: $10.1177 / 1940161208319098$ 
Van Zoonen, L. (2006). The personal, the political and the popular: A woman's guide to celebrity politics. European journal of cultural studies, 9(3), 287-301. DOI: $10.1177 / 1367549406066074$

Wattenberg, M. (1984). The decline of American political parties, 1952-1980. Cambridge, MA: Harvard University Press.

West, D. M. (2005). American politics in the age of celebrity. The Hedgehog Review, 7(1), 59-66.

Wheeler, M. (2012). The democratic worth of celebrity politics in an era of late modernity. The British Journal of Politics and International Relations, 14(3), 407-422.

Wood, M., Corbett, J., \& Flinders, M. (2016). Just like us: Everyday celebrity politicians and the pursuit of popularity in an age of anti-politics. The British Journal of Politics and International Relations, 18(3), 581-598. DOI: 10.1177/1369148116632182

Yin, Robert K. (2002). Case Study Research: Design and Methods. London: Sage Publications.

\section{Berita dan internet}

Dejevsky, Mary. (2019, 2019, 18 April). Why a new era of anti-politics will probably help a TV comedian win Ukraine's presidential election. https://www.independent.co.uk/voices/ukraine-election-president-volodymyr-zelenskypetro-poroshenko-a8875951.html. Diakses pada 5 Mei 2019.

Kao, Anthony (2017, 22 Agustus). Interview: Vladimir Zelenskiy on Playing Ukraine's President "Servant of the People". https://www.cinemaescapist.com/2017/08/interview-vladimir-zelenskiy-playingukraines-president-servant-people/. Diakses pada 3 Mei 2019.

Kao, Anthony. (2017, 6 Juni). Ukraine's "Servant of the People" Is a Hidden Gem of Political Comedy. https://www.cinemaescapist.com/2017/06/ukraines-servant-peoplehidden-gem-political-comedy/. Diakses pada 3 Mei 2019.

Team Zelenskiy: behind the scenes in Ukraine election win. (2019, 22 April). https://www.reuters.com/article/us-ukraine-election-team/team-zelenskiy-behind-thescenes-in-ukraine-election-win-idUSKCN1RY0XF. Diakses pada 2 Mei 2019).

Ukraine election: Poroshenko debates empty podium as Zelensky stays away. (2019, 14 April). BBC.com. https://www.bbc.com/news/world-europe-47925330. Diakses pada 2 Mei 2019.

Ukraine media demands access to runoff frontrunner Zelensky. (2019, 17 April). Al Jazeera. https://www.aljazeera.com/news/2019/04/ukraine-media-demands-access-frontrunnervolodymyr-zelensky-190416154745843.html. Diakses pada 3 Mei 2019.

Ukraine's Election Is an All-Out Disinformation Battle. (2019, 17 April). The Atlantic. https://www.theatlantic.com/international/archive/2019/04/russia-disinformationukraine-election/587179/. Diakses pada 2 Mei 2019.

Vladimir Zelenskiy. (2019). Tersedia dari: http://kvartal95.com/en/actors/vladimir/

Volnsky, Oleksandr. (2018, 17 April). Presidential elections in Ukraine - the show will end, but what will happen to the country?. https://www.ukrinform.net/rubric- 
elections/2683041-presidential-elections-in-ukraine-the-show-will-end-but-what-willhappen-to-the-country.html. Diakses pada 3 Mei 2019.

Zelenskiy reveals plans to end war with Russia, fight corruption. (2019, 8 April). https://www.kyivpost.com/ukraine-politics/zelenskiy-reveals-plans-to-end-war-withrussia-fight-corruption.html. Diakses pada 5 Mei 2019.

Zelensky faces first challenges ahead of presidential inauguration. (2019, 26 April). http://www.ukrweekly.com/uwwp/zelensky-faces-first-challenges-ahead-ofpresidential-inauguration/. Diakses 5 Mei 2019).

Zelensky promises to maintain Ukraine's course toward NATO and EU and protect foreign investments.. (2019, April 8). Uawire. https://uawire.org/zelensky-promises-tomaintain-ukraine-s-course-toward-nato-and-eu-and-protect-foreign-investments\#. Diakses pada 5 Mei 2019.

Zelensky says Ukraine and Russia share only state border, have nothing else in common. (2019, 2 Mei). http://tass.com/world/1056799. Diakses pada 5 Mei 2019.

Zelensky supports legalization of prostitution, marijuana in Ukraine: Ukraine could have own Las Vegas. (2019, 18 April). https://www.unian.info/politics/10521186-zelenskysupports-legalization-of-prostitution-marijuana-in-ukraine-ukraine-could-have-own-lasvegas.html. Diakses pada 5 Mei 2019. 